\section{Meningitis e hipoacusia por manipulación de carne porcina}

\author{
Juan Moraga', Alberto Fica1,2, Braulio Navarrete ${ }^{1,2}$, \\ Ruby Henríquez ${ }^{1,2}$ y Claudio Navarrete Asenjo ${ }^{1,2}$
}

\begin{abstract}
Meningitis and hypoacusia due to swine meat handling
Zoonotic meningitis by Streptococcus suis has been described occasionally in Chile and linked to pig farmers in the south of the country. We report a female case that developed acute bacterial meningitis by this agent, two days after handling a piece of raw swine meat. She did not participate on swine breeding nor visited farms. Diagnosis was obtained by CSF culture. A severe hearing loss and not recovered despite corticosteroids use and antimicrobial treatment, without others complications. Meningitis by S. suis is emerging as a new pathogen and linked to swine in different forms. Hypoacusis happens frequently with this agent.

Keywords: Bacterial meningitis; Streptococcus suis; hearing loss; swine.

Palabras clave: Meningitis bacteria; Streptococcus suis; hipoacusia; cerdo.
\end{abstract}

\section{Introducción}

L as infecciones zoonóticas por Streptococcus suis, ligadas a la crianza, transporte o manipulación de cerdos o carne porcina, son relevantes en Asia y suceden hasta ahora esporádicamente en países occidentales. Luego de la descripción de los dos primeros casos en Chile, el año 2013 asociados a cuadros de meningitis aguda y ligados a la crianza de cerdos en el $\operatorname{sur}^{1}$, no se han publicado más casos en la literatura médica nacional convirtiendo esa comunicación en un dato anecdótico. Recientemente, hemos observado otro caso en la Región de Los Ríos que deseamos comunicar por sus dificultades diagnósticas, secuelas y mecanismo de contagio.

\section{Caso clínico}

Mujer de 44 años sin antecedentes mórbidos, que consultó en el Servicio de Urgencias de nuestro hospital en febrero de 2018 por compromiso del

'Hospital Base de Valdivia.

${ }^{2}$ Universidad Austral de Chile.

Financiamiento: Ninguno.

Conflictos de interés: Ninguno.

Recibido: 24 de abril de 2018 / Aceptado: 6 de noviembre de 2018

Correspondencia a:

Alberto Fica

albertoficacubillos@gmail.com estado general, cefalea, vómitos y sensación febril de cuatro días, agregándose el último día disminución en la audición bilateral. Al ingreso estaba vigil, afebril, sin taquicardia, normotensa, con una hipoacusia bilateral, con signos meníngeos, sin otra focalidad neurológica. En el estudio de laboratorio destacaba un hemograma con leucocitosis de 24.680 céls $/ \mathrm{mm}^{3}$, $92 \%$ neutrófilos, PCR $25,35 \mathrm{mg} / \mathrm{dL}$ (referencia $<0,5 \mathrm{mg} / \mathrm{dL}$ ) y un estudio del LCR que dio salida de líquido turbio a tensión, proteinorraquia 170 $\mathrm{mg} / \mathrm{dl}$, glucorraquia $<2 \mathrm{mg} / \mathrm{dl}$ y pleocitosis de 2.500 cél $/ \mathrm{mm}^{3}$, con $80 \%$ polimorfonucleares. En la tinción de Gram se observaron cocáceas grampositivas en cadenas cortas y el panel molecular de meningitis (FilmArray Meningitis/Encefalitis panel) fue negativo. No se tomaron hemocultivos. Se hospitalizó en la Unidad de Paciente Crítico con el diagnóstico de una meningitis bacteriana aguda, iniciándose ceftriaxona i.v (2 g cada $12 \mathrm{~h}$ ) más dexametasona i.v. $(10 \mathrm{mg}$ cada $6 \mathrm{~h}$ ). La paciente persistió con cefalea holocránea intensa (escala visual análoga 8 de 10) y la evaluación por otorrinolaringología confirmó una hipoacusia sensorio-neural sin un foco ótico infeccioso asociado. El estudio tomográfico de fosa posterior con medio de contraste resultó normal. La audiometría confirmó una hipoacusia profunda bilateral (Figura 1) con timpanometría normal, descartando este último examen compromiso timpánico.

El cultivo del LCR demostró a las $12 \mathrm{~h}$ la presencia de cocáceas grampositivas en cadena con colonias alfa-hemolíticas en las placas de agar sangre, las que fueron informadas al día siguiente como Streptococcus sanguinis (Vitek 2 Compact, Biomerieux). El estudio de susceptibilidad señaló actividad de ceftriaxona (CIM $0,064 \mu \mathrm{g} / \mathrm{mL}$ ) y penicilina (CIM 0,032 $\mu \mathrm{g} / \mathrm{mL}$ ). La derivación de la cepa al Laboratorio de Referencia cambió posteriormente el diagnóstico a colonias $\beta$-hemolíticas que fueron identificadas como $S$. suis perteneciente al serotipo 2. El diagnóstico fue respaldado por pruebas bioquímicas, espectrometría de masas y secuenciación del gen ARN16S realizados en el Laboratorio de Meningitis Bacteriana, Instituto de Salud Pública de Chile.

La anamnesis dirigida de la paciente logró rescatar el antecedente de contacto con carne de cerdo cruda faenado en forma artesanal en otra localidad a la de la residencia de la paciente, el que había recibido de

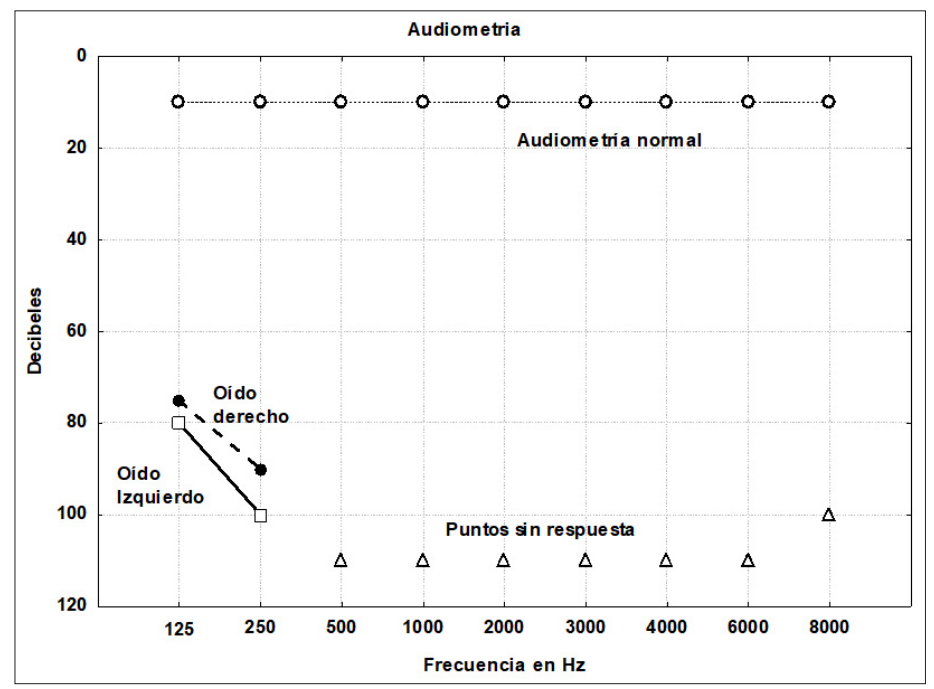

Figura 1. Audiometría que indica una hipoacusia profunda bilateral. La tasa de secuelas auditivas es mayor con este agente respecto a otras causas de meningitis bacteriana. 
regalo dos días antes de iniciar su sintomatología. La paciente estuvo expuesta aproximadamente unos cuatro minutos en contacto directo con parte del animal faenado, mientras se tomaba fotografías. En ese momento no presentaba lesiones cutáneas. En su lugar de residencia no tenía crianza propia de cerdos ni había visitado sitios dedicados a ello, por lo que se asumió este evento como el único momento de contacto potencial. Otros familiares no enfermaron. La evaluación complementaria con ecocardiografía transtorácica y transesofágica descartó una endocarditis. La paciente evolucionó de forma favorable, completando 17 días con ceftriaxona y fue dada de alta. En un control posterior se realizó un examen de potenciales evocados auditivos que confirmó la hipoacusia profunda sensorioneural bilateral. Actualmente, se encuentra en espera de un implante coclear.

\section{Discusión}

Esta comunicación demuestra la continua presencia de S. suis como agente zoonótico en la Región de Los Ríos, siendo este el tercer caso publicado de meningitis bacteriana aguda, los anteriores ocurridos el año $2012^{1}$, todos ellos asociados al serotipo 2, el de mayor importancia para el ser humano. Otros dos casos de infección por este microorganismo han sido comunicados en la Región de los Ríos en los años 2014 y 2015, ligados a un cuadro de sepsis grave y meningitis; respectivamente. Ninguno de los casos registrados hasta ahora en esta región ha sucedido en la misma ciudad o pueblo (comunicación personal: Velásquez JC, epidemiólogo, Hospital Base de Valdivia). En nuestro caso, no hubo una asociación con crianza de cerdos sino con un contacto fortuito con carne faenada ampliando los escenarios de contagio. Debido a que no se identificó $\beta$-hemólisis en las pruebas locales iniciales, se atrasó el reconocimiento inicial de este patógeno ${ }^{2}$. Además, el panel molecular de meningitis comercial usado (Filmarray, BioMerieux), no demostró agente alguno por no contar en su batería con esta alternativa etiológica. Este agente podría ser sospechado frente a la presencia de cocáceas grampositivas con disposición en cadena en el LCR con actividad $\beta$-hemolítica, ya que $S$. pneumoniae no produce hemólisis. Este caso también demuestra las limitaciones de los paneles moleculares integrados que se concentran en diagnosticar etiologías prevalentes en países occidentales, pero no tienen la capacidad de detectar agentes inusuales o relevantes en otros contextos epidemiológicos. De hecho, este agente es el más frecuente en casos de meningitis bacteriana aguda en algunos países del sudeste asiático ${ }^{3}$. Es de interés también destacar la hipoglucorraquia extrema y la alta tasa de secuelas auditivas asociadas a esta especie, y cuya frecuencia se reduce con el uso de corticoesteroides, aunque en este caso no demostró tener impacto ${ }^{3,4}$.

Streptococcus suis se agrega a una lista de patógenos emergentes o geográficos propios del sur de Chile y que incluyen la fiebre de los matorrales ${ }^{5}$, el síndrome cardiopulmonar por el virus $\operatorname{Andes}^{6,7}$. hidatidosis ${ }^{8}$, difilobotriasis ${ }^{9,10}$, e incluso la enfermedad de Hansen en inmigrantes (San Martín A y cols., en este número). En cada uno de estos casos, la búsqueda de antecedentes epidemiológicos es relevante para establecer una sospecha adecuada.

Nota del editor: Si bien es una zoonosis emergente, en Chile se describieron los primeros casos de infección por $S$. suis en humanos el año 2012. El caso aquí presentado sería el cuarto caso de meningitis en la Región de los Ríos y como infección invasora por S. suis sería el sexto, debido a que el Laboratorio de Referencia (ISP) ha confirmado hasta la fecha cuatro cepas de LCR y dos de sangre procedentes del Hospital de Valdivia; todos correspondientes al serotipo 2. (Comunicación personal: Pedro Alarcón, Laboratorio de Agentes Infecciosos, Bacteriología, ISP). Tal vez, antes del año 2012 estábamos subdiagnosticando casos por $S$. suis, lo cual refleja que en la actualidad los laboratorios están mejorando su capacidad técnica de identificación, lo cual acompañado de la clínica del paciente y los antecedentes epidemiológicos, debe alertar al equipo de salud frente a la sospecha de este agente.

\section{Resumen}

En Chile se han descrito ocasionalmente casos de meningitis zoonótica por Streptococcus suis ligados a criaderos de cerdos en el sur del país. Presentamos el caso de una mujer que desarrolló un cuadro de meningitis aguda bacteriana por este agente dos días después de manipular un cerdo faenado. No tenía crianza de cerdos ni visitaba granjas de animales. El diagnóstico fue establecido por el cultivo del LCR. Desarrolló una hipoacusia profunda que no mejoró a pesar del uso de corticoesteroides ni tratamiento antimicrobiano, sin otras complicaciones. La meningitis por $S$. suis es una condición emergente y ligada a porcinos en diferentes formas. La hipoacusia es una complicación frecuente con este agente.

\section{Referencias bibliográficas}

1.- Koch E, Fuentes G, Carvajal R, Palma R, Aguirre V, Cruz C, et al. Meningitis bacteriana aguda por Streptococcus suis en criadores de cerdos: comunicación de los primeros dos casos en Chile. Rev Chilena Infectol 2013; 30: 557-61.

2.- Alarcón P. Streptococcus suis. Retrato Microbiológico. Rev Chilena Infectol 2012; 29: 541-2.

3.- $\quad$ Mai N T, Hoa N T, Nga T V, Linh le D, Chau T T, Sinh D X, et al. Streptococcus suis meningitis in adults in Vietnam. Clin Infect Dis 2008; 46: 659-67.

4.- $\quad$ Huong V T, Long H B, Kinh N V, Hgan TT, Dung V T, Nadjm B, et al. Long-term outcomes of Streptococcus suis infection in Vietnam: a casecontrol study. J Infection 2018; 76: 159-67.

5.- Weitzel T, Dittrich S, López J, Phuklia W, Martinez-Valdebenito C, Velásquez K, et al. Endemic scrub typhus in South America. N Engl J Med 2016; 375: 954-61.

6.- Navarrete M, Hott M, Caroca J, Leyton L, Venegas N, Ismail K, et al. Correlación entre criterios clínicos y de laboratorio de casos notificados por sospecha de hantavirosis y el resultado de la técnica de referencia. Rev Chilena Infectol 2016; 33: 275-81.

7.- Täger Frey M, Vial P C, Castillo C H, Godoy P M, Hjelle B, Ferrés M G. Hantavirus prevalence in the IX region of Chile. Emerg Infect Dis 2003; 9: 827-32.

8.- Martínez P. Hidatidosis humana: antecedentes generales y situación epidemiológica en Chile, 2001-2009. Rev Chilena Infectol 2011; 28: 58591.

9.- $\quad$ Torres P, Franjola R, Pérez J, Auad S, Uherek F, Miranda J C, et al. Epidemiología de la difilobotriasis en la cuenca del río Valdivia, Chile. Rev Saude Publica 1989; 23: 45-57.

10.- Cabello F C. Acuicultura y salud pública. La expansión de la difilobotriasis en Chile y en el mundo. Rev Med Chile 2007; 135: 1064-71. 